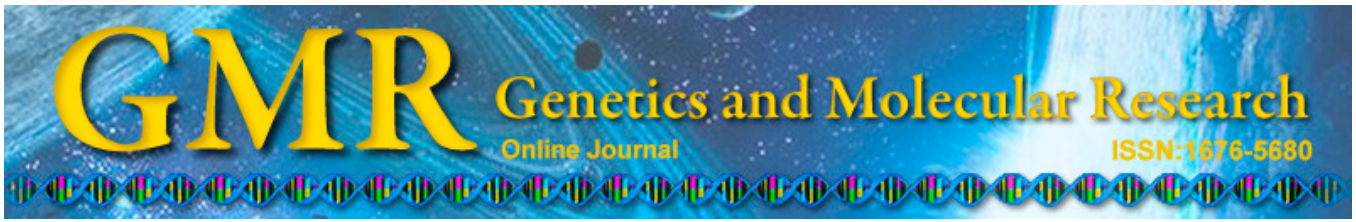

\title{
A simplified genomic DNA extraction protocol for pre-germination genotyping in rice
}

Y.B. Duan ${ }^{1}$, F.L. Zhao ${ }^{1}$, H.D. Chen ${ }^{1}$, H. Li' ${ }^{2}$, D.H. Ni², P.C. Wei², W. Sheng1, J.T. Teng ${ }^{1}$, A.M. Zhang ${ }^{1}$ and J.P. Xue ${ }^{1}$

${ }^{1}$ Key Laboratory of Resource Plant Biology of Anhui Province, College of Life Sciences, Huaibei Normal University, Huaibei, China

${ }^{2}$ Key Laboratory of Rice Genetics Breeding of Anhui Province, Rice Research Institute, Anhui Academy of Agricultural Sciences, Hefei, China

Corresponding author: J.P. Xue

E-mail: xuejp@163.com

Genet. Mol. Res. 14 (2): 6369-6375 (2015)

Received October 13, 2014

Accepted February 19, 2015

Published June 11, 2015

DOI http://dx.doi.org/10.4238/2015.June.11.12

\begin{abstract}
Genotyping is a critical step for molecular markerassisted selection in rice. Rice genomic DNA samples for genotyping are typically isolated from living tissues such as seedlings. This requires the germination of all candidate seeds and extraction of DNA from the seedlings. Currently, an ideal individual is selected from a very large number of plants, which is time- and labor-consuming, requiring several transplantations of materials and sampling processes. In this study, we developed a simplified genomic DNA extraction protocol in rice by using amylase to treat half-seeds. The yields of genomic DNA from a half-seed of Indica and Japonica rice were greater than $203.8 \pm$ 32.5 and $143.2 \pm 25.5 \mathrm{ng}$, respectively, and the 260/280 $\mathrm{nm}$ absorbance ratio was $1.75-2.10$. The DNA was confirmed to be sufficient for polymerase chain reaction amplification and can be used in a markerassisted selection program.
\end{abstract}

Key words: DNA extraction; Half-seed; Polymerase chain reaction; Pre-germination genotyping; Oryza sativa L. 


\section{INTRODUCTION}

Molecular marker-assisted selection (MAS) plays an important role in modern breeding programs, particularly when transgenic crops are confronted with public concern for their potential risks (Bawa and Anilakumar, 2013). Rather than observational and experience-dependent indirect selection methods used in traditional breeding, MAS employs molecular detection and monitoring of genes of interest to control corresponding traits. Moreover, MAS can be used to select and pyramid genes controlling traits that cannot be detected during the plant growth period, such as high accumulation or reduction of amino acids and fatty acids caused by nucleotide mutations (Li et al., 2007; Ni et al., 2011; Jiang et al., 2014). Rice (Oryza sativa) is a staple food that feeds over $50 \%$ of the world's population; thus, rice is important in global food security. Breeding techniques used for rice have attracted worldwide concern from both the public and private sectors. MAS has been broadly applied in rice in previous studies (Jena and Mackill, 2008).

Extraction of high-quality DNA is a prerequisite for MAS studies. Numerous DNA extraction protocols have been developed for rice (Clark and Krysan, 2007; Li et al., 2013). However, these protocols typically involve the use of living organs such as green leaves as experimental materials, requiring researchers to germinate the seeds and to select the target plants at the seedling stage based on polymerase chain reaction (PCR) amplification results. In modern molecular breeding, a desirable individual may be selected from among 1000 or even 10,000 candidates. If all candidate seeds are germinated and grown into seedlings for sampling, transplantation of materials and sampling become difficult. To resolve this limitation, Chunwongse et al. (1993) initiated a non-destructive detection method by extracting genomic DNA from triploid embryos but with an identical genome to other organs, providing breeders with the flexibility to perform MAS during off-seasons and at out-stations. A seed can be transversely cut into 2 portions, and the portion without the embryo can be used to extract genomic DNA for genotyping, while the other can be applied for further experiments if selected.

A simple DNA extraction method was previously established in barley using a 1-mm drill bit to collect the endosperm powder (von Post et al., 2003). Additionally, seed DNA-based pre-germination has been successfully developed and used in maize (Gao et al., 2008), which was likely accomplished because of the relatively large size of maize seed. DNA extraction from seed has been described using single dry seeds from other species as well (Kang et al., 1998).

As a small-sized plant species, the 1000-grain weight of rice varieties commonly ranges from 20 to $32 \mathrm{~g}$ (Sarhadi et al., 2009). This indicates that a half-seed is typically 10-16 $\mathrm{mg}$ in weight, requiring a highly efficient and simplified procedure to harvest sufficient amounts of genomic DNA. In the rice endosperm, starch accounts for approximately $80 \%$ of the total weight of rice seed. In the present study, we developed a simplified protocol for isolating rice genomic DNA from half-seeds by using amylase to degrade the starch before DNA isolation.

\section{MATERIAL AND METHODS}

\section{Materials}

Dried seeds of wild-type $O$. sativa Japonica cv Nipponbare, hygromycin resistance gene-transgenic Nipponbare (Duan et al., 2012), and an isogenic Indica 75-1-127 line harboring the rice blast gene $P i 9(t)$ (Ni et al., 2007) were used in this study. 


\section{Reagents}

Starch degradation buffer ( $2 \%$ amylase buffer) was prepared by dissolving $2 \mathrm{~g}$ amylase in $100 \mathrm{~mL} \mathrm{ddH_{2 }} \mathrm{O}$. Additionally, $100 \mu \mathrm{M} \mathrm{NaOH}$ was prepared by dissolving $0.4 \mathrm{~g} \mathrm{NaOH}$ in $100 \mathrm{~mL}$ deionized water. To prepare $70 \%$ ethanol, we mixed $70 \mathrm{~mL}$ anhydrous ethanol with $30 \mathrm{~mL}$ deionized water.

\section{DNA extraction protocol}

A seed was transversely cut into 2 portions, 1 without the embryo for DNA isolation and the other that could be used for further germination testing. The portion for DNA isolation was cut into 5 pieces, and 4 intact seeds were cut into small pieces as a control. The materials were immersed in $200 \mu \mathrm{L} 2 \%$ amylase solution at $42^{\circ} \mathrm{C}$ overnight. The sample was centrifuged at $9500 \mathrm{~g}$ for $1 \mathrm{~min}$, and the supernatant was discarded. Next, $200 \mu \mathrm{L} 0.1 \mathrm{M} \mathrm{NaOH}$ was added and the cells were lysed for $30 \mathrm{~min}$. The sample was centrifuged at $9500 \mathrm{~g}$ for $10 \mathrm{~min}$ and the supernatant was collected. An equal volume of pre-cooled anhydrous ethanol was added for precipitation. The sample was centrifuged at $9500 \mathrm{~g}$ for $10 \mathrm{~min}$ and the supernatant was discarded. After air-drying, the precipitate was dissolved in $50 \mu \mathrm{LddH}_{2} \mathrm{O}$ and preserved at $-20^{\circ} \mathrm{C}$.

\section{Assessment of genomic DNA quality}

To assess the quality of genomic DNA, $2 \mu \mathrm{L}$ of each DNA sample was subjected to electrophoresis on a $0.8 \%$ agarose gel, and another $1 \mu \mathrm{L}$ was used for quantification using a NanoDrop 2000 spectrophotometer (Thermo Scientific, Waltham, MA, USA). Each sample was measured 3 times. The concentration of DNA was calculated based on the absorbance at $260 \mathrm{~nm}$. The ratio of nucleic acids to proteins in the genomic DNA was evaluated using the ratio of absorbance at 260 and $280 \mathrm{~nm}\left(A_{260} / A_{280}\right.$ ratio; Sambrook and Russell, 2001).

\section{PCR amplification and agarose gel electrophoresis}

PCR was performed in a $25-\mu \mathrm{L}$ volume reaction system, containing of $1 \mathrm{X}$ PCR buffer ( $\mathrm{Mg}^{2+}$ plus), $1.0 \mathrm{mM}$ dNTPs, $2 \mu \mathrm{M}$ of each forward and reverse primer, 10 ng template DNA, $0.1 \mathrm{U} \mathrm{Taq}$ DNA polymerase. Two genes were tested in this study, including the hygromycin resistance gene Hpt (Hpt-F 5'-CGC CGA TGG TTT CTA CAA-3' and Hpt-R 5'-GGC GTC GGT TTC CAC TAT-3') and the rice blast resistance gene $P i 9(t)$-associated marker pB8 (pB8F 5'-CCGGACTAAGTACTGGCTTCGATA-3' and pB8-R 5'-CCCAATCTCCAATGACCCA TAAC-3'). The amplification reaction was performed at $94^{\circ} \mathrm{C}$ for $5 \mathrm{~min}$, followed by 35 cycles of $94^{\circ} \mathrm{C}$ for $30 \mathrm{~s}, 58^{\circ} \mathrm{C}$ for $30 \mathrm{~s}$, and $72^{\circ} \mathrm{C}$ for $45 \mathrm{~s}$, and then at $72^{\circ} \mathrm{C}$ for $7 \mathrm{~min}$ for final extension. The PCR products were detected by fractionation on a $1.0 \%$ agarose gel using $1 \mathrm{X}$ Tris/ Acetate/EDTA buffer containing $10 \mathrm{mg} / \mathrm{mL}$ ethidium bromide and visualized under an ultraviolet gel documentation system.

\section{Germination experiment}

The remnant half-seeds with embryos were used to examine their germination and growth ability, which were compared with those of intact seeds. The seeds tested were surface- 
sterilized with $2 \% \mathrm{NaClO}$ for 20 min, rinsed with sterilized $\mathrm{ddH}_{2} \mathrm{O} 5$ times, and immersed in $\mathrm{ddH}_{2} \mathrm{O}$ at $37^{\circ} \mathrm{C}$ overnight. The seeds were then transferred to Petri dishes containing 4 layers of gauze for moisture maintenance, and incubated in a $30^{\circ} \mathrm{C}$ incubator.

\section{RESULTS}

\section{DNA quality and quantity}

To meet the requirements for subsequent molecular studies, we assessed the DNA samples qualitatively and quantitatively. The genomic DNA extracted from the 2 intact seeds exhibited a single band on gel electrophoresis, while that from the half-seeds was relatively weak or even invisible (Figure 1). This suggests that the amount of genomic DNA purified from limited materials (approximately 10-15 mg) was difficult to detect. Nanodrop analysis showed that the yield of genomic DNA was $143.2 \pm 25.5 \mathrm{ng}$ from a half-seed of Japonica Nipponbare, and was $203.8 \pm 32.5 \mathrm{ng}$ from a half-seed of Indica 75-1-127; the absorbance $\left(A_{260}\right.$ $A_{280}$ ) ratio was $1.75-2.10$ (Table 1$)$.

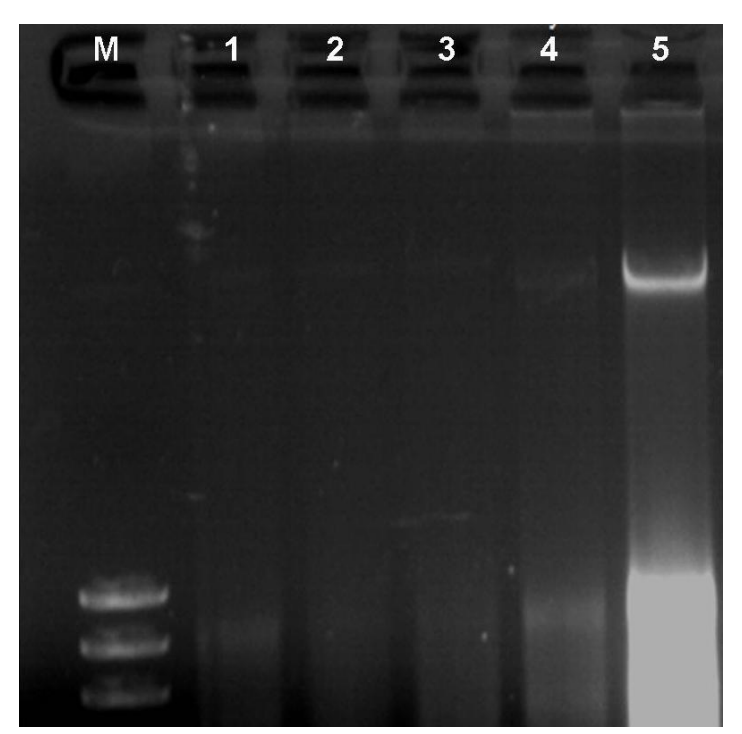

Figure 1. Electrophoresis pattern of genomic DNA extracted from a half-seed of rice. Lane $M=$ DNA marker DL 2000; lanes 1-2 = Nipponbare; lanes 3-4 = Indica 75-1-127.

Table 1. Purity and yield of DNA extracted using the simplified protocol.

\begin{tabular}{lccc}
\hline Sample & $A_{260} / A_{280}$ & $A_{260} / A_{280}$ & Yield (ng) \\
\hline 75 -1-127 (half-seed) & $1.79 \pm 0.03$ & $2.07 \pm 0.07$ & $203.8 \pm 32.5$ \\
Hpt gene-transgenic Nipponbare (half-seed) & $1.79 \pm 0.04$ & $2.10 \pm 0.04$ & $145.8 \pm 21.2$ \\
Wild-type Nipponbare (half-seed) & $1.78 \pm 0.03$ & $2.05 \pm 0.05$ & $143.2 \pm 25.5$ \\
Nipponbare (4 seeds) & $2.04 \pm 0.05$ & $2.26 \pm 0.06$ & $1620.5 \pm 210.3$ \\
\hline
\end{tabular}




\section{PCR amplification results}

We used dried seeds from a homozygous Nipponbare line harboring the $\mathrm{Hpt}$ gene and an isogenic 75-1-127 line harboring the rice blast gene $P i 9(t)$. The PCR results are shown in Figures 2 and 3. The results showed that the genomic DNA extracted from the half-seeds of rice using the simplified protocol established in this study was suitable for amplification of gene fragments ranging from 500 to 800 base pairs in length.

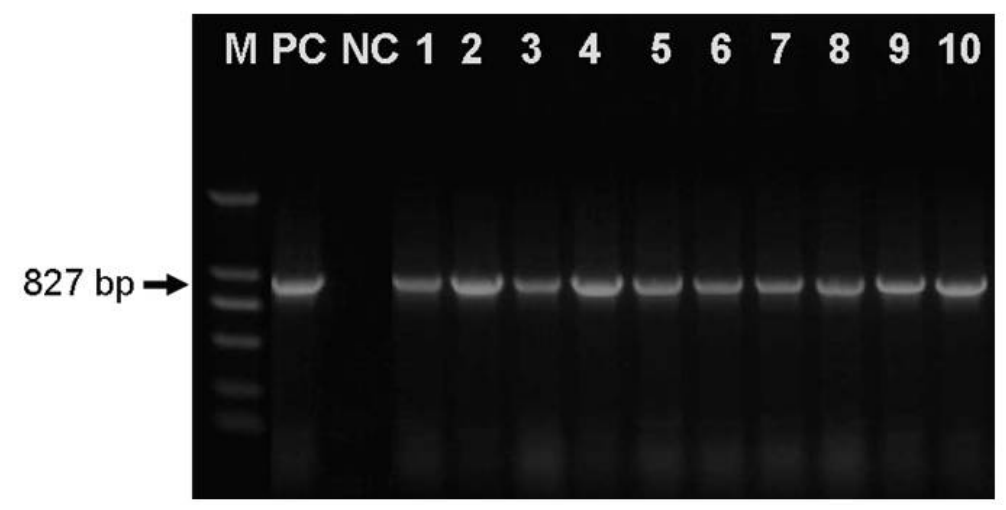

Figure 2. Results of PCR amplification to detect transgenic Nipponbare seeds harboring the Hpt gene. Lane M=DNA marker DL 2000; lane $P C=$ positive control pCAMBIA13081 plasmid; lane $N C=$ negative control $\mathrm{ddH}_{2} \mathrm{O}$; lanes 1-10 $=$ different homozygous transgenic seeds.

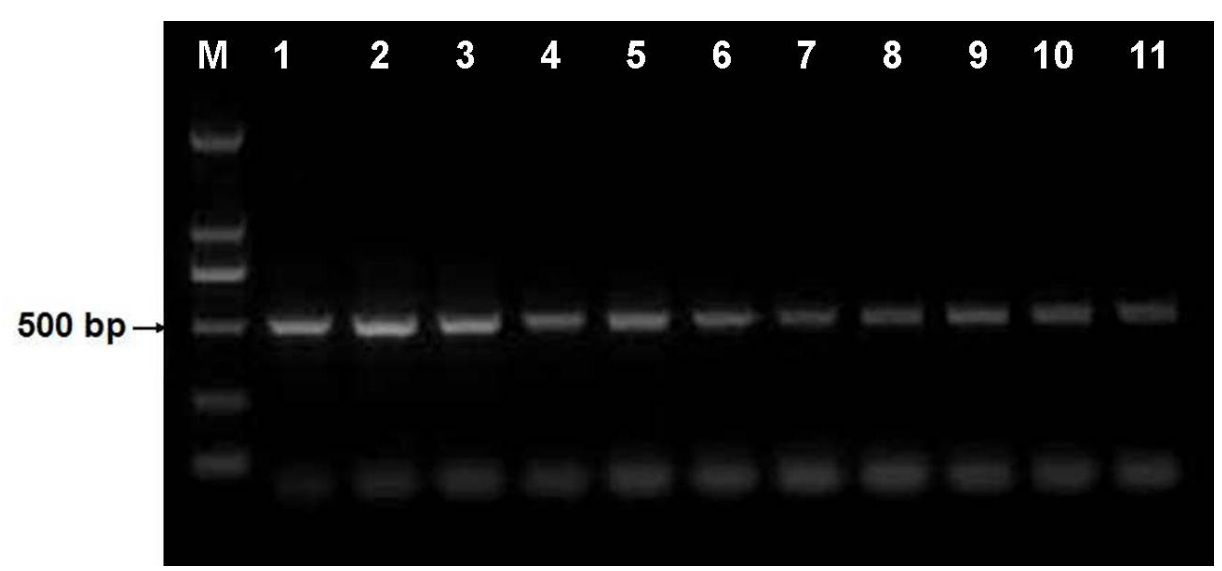

Figure 3. Results of PCR amplification to detect an isogenic 75-1-127 line harboring the rice blast gene Pi $9(t)$. Lane $M=$ DNA marker DL 2000; lanes $1-11=$ different seeds.

\section{Germination ability assessment}

The germination experiment indicated that half-seeds shared the same germination and growth ability with intact seeds, although the growth was relatively slower (Figure 4). 


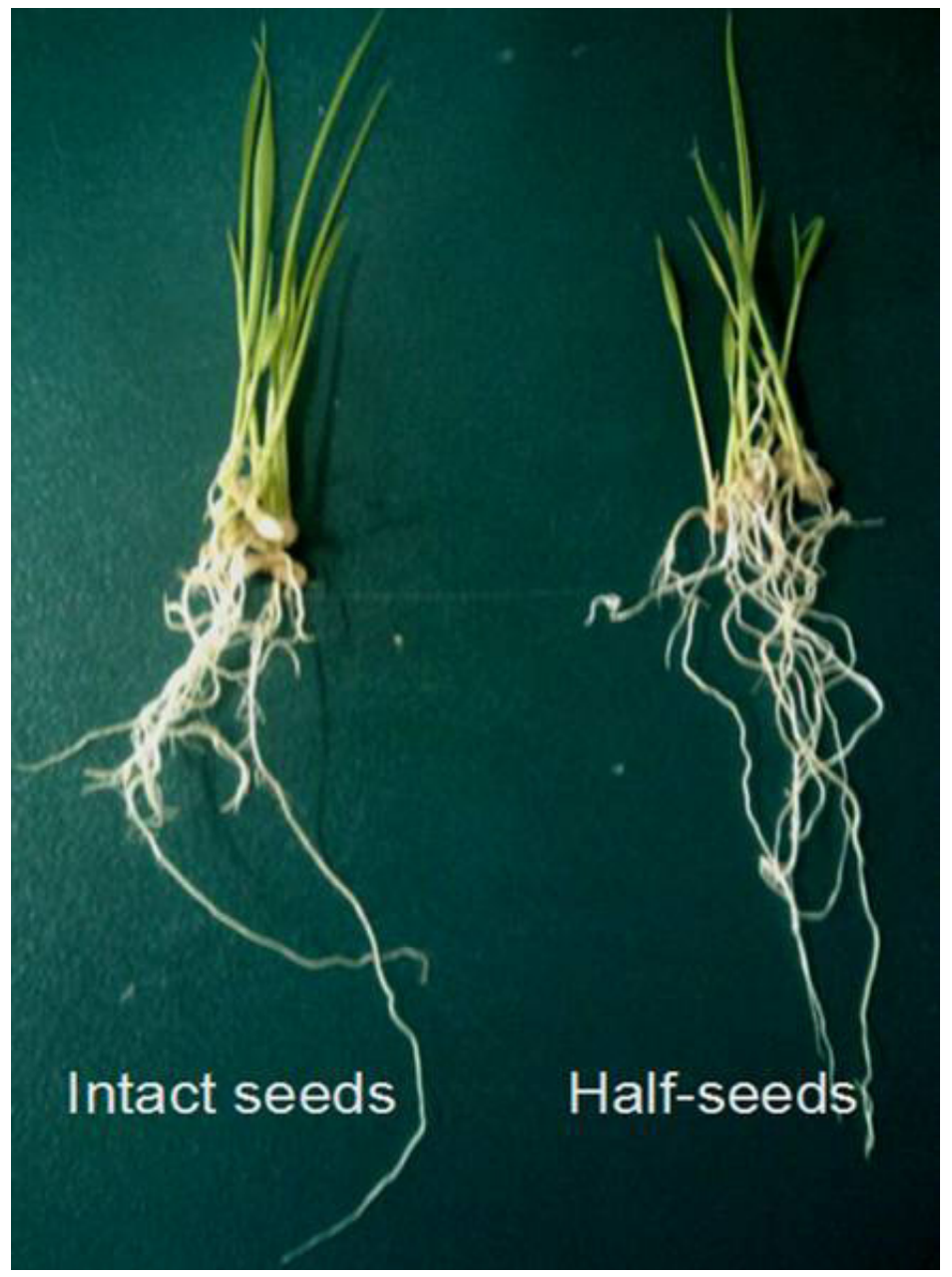

Figure 4. Comparison of growth ability between half-seeds and intact seeds.

\section{DISCUSSION}

For large-scale pre-germination genotyping analysis, the genomic DNA extraction procedure must be very simple and inexpensive. The limited amount of material (half-seed) is a limitation in genomic DNA extraction, particularly for small grain crops such as rice. Traditional cetyl trimethylammonium bromide or sodium dodecyl sulfate methods typically require thorough grinding of materials into powder using liquid nitrogen or silica, which is relatively difficult for rice grains with very hard surfaces. Moreover, these methods are generally phenol-chloroform-dependent, and may involve the use of hazardous reagents that require special handling and waste disposal (Sambrook et al., 2002). In addition, other protocols use expensive reagents such as proteinase $\mathrm{K}$ in the DNA isolation process (Borges et al., 2012), making these procedures difficult to apply on a large scale.

In the present study, amylase was used to degrade the starch prior to DNA isolation, 
and then $\mathrm{NaOH}$ was used for cell lysis to release genomic DNA. The starch lysis can be conducted at the end of the first day, and other procedures can be completed within a very short period of time on the second day, reducing the time required for DNA isolation. Moreover, this method uses several very common, toxicity-free, and inexpensive chemicals, and thus it is simple, safe, and inexpensive. In summary, we developed a simplified and efficient protocol for extracting genomic DNA from half-seeds of rice, which may facilitate its large-scale use and promote the commercial application of pre-germination genotyping in rice.

\section{ACKNOWLEDGMENTS}

Research supported by the Key Project of the Natural Science Foundation of Universities in Anhui Province (\#KJ2014A226), the National Natural Science Foundation of China (\#30973963), the Natural Science Foundation of Anhui Province (\#1408085MC58), and the Open Project Program of Key Laboratory of Resource Plant Biology of Anhui Province (\#ZYZWSW2014001).

\section{REFERENCES}

Bawa AS and Anilakumar KR (2013). Genetically modified foods: safety, risks and public concerns - a review. J. Food Sci. Technol. 6: 1035-1046.

Borges DB, Amorim MB, Waldschmidt AM, Mariano-Neto E, et al. (2012). Optimization of DNA extraction from fresh leaf tissues of Melanoxylon brauna (Fabaceae). Genet. Mol. Res. 11: 1586-1591.

Chunwongse J, Martin GB and Tanksley SD (1993). Pre-germination genotypic screening using PCR amplification of half-seeds. Theor. Appl. Genet. 86: 694-698.

Clark KA and Krysan PJ (2007). Protocol: An improved high-throughput method for generating tissue samples in 96-well format for plant genotyping (Ice-Cap 2.0). Plant Methods 3: 8.

Duan YB, Zhai CG, Li H, Li J, et al. (2012). An efficient and high-throughput protocol for Agrobacterium-mediated transformation based on phosphomannose isomerase positive selection in Japonica rice (Oryza sativa L.). Plant Cell Rep. 31: 1611-1624.

Gao SB, Martinez C, Skinner DJ, Krivanek AF, et al. (2008). Development of a seed DNA-based genotyping system for marker-assisted selection in maize. Mol. Breed. 22: 477-494.

Jena KK and Mackill DJ (2008). Molecular markers and their use in marker-assisted selection in rice. Crop Sci. 4: 1266-1276.

Jiang C, Shi J, Li R, Long Y, et al. (2014). Quantitative trait loci that control the oil content variation of rapeseed (Brassica napus L.). Theor. Appl. Genet. 127: 957-968.

Kang HW, Cho YG, Yoon UH, Eun MY, et al. (1998). A rapid DNA extraction method for RFLP and PCR analysis from single dry seed. Plant Mol. Biol. Rep. 16: 1-9.

Li H, Li J, Cong XH, Duan Y, et al. (2013). A high-throughput, high-quality plant genomic DNA extraction protocol. Genet. Mol. Res. 12: 4526-4539.

Li YC, Hu Q, Mei DS, Li YD, et al. (2007). Molecular assisted breeding and adaptability analysis of Zhongyouza 11 with super high oil content. Agric. Sci. China 6: 1306-1314.

Ni DH, Yi CX, Yang JB, Wang XF, et al. (2007). Pyramiding $P i 9(t)$ and $X a 23$ genes by molecular marker-assisted selection. Mol. Plant Breed. 5: 491-496.

Ni DH, Zhang SL, Chen S, Xu Y, et al. (2011). Improving cooking and eating quality of Xieyou57, an elite indica hybrid rice, by marker-assisted selection of the Wx locus. Euphytica 179: 355-362.

Sambrook J and Russell DW (2001). Molecular Cloning, a Laboratory Manual. Cold Spring Harbor Laboratory Press, Cold Spring Harbor.

Sambrook J, Fritsch EF and Maniatis T (2002). Molecular Cloning: A Laboratory Manual. Cold Spring Harbor Laboratory Press, Cold Spring Harbor.

Sarhadi WA, Ookawa T, Yashihashi T, Madadi, AK, et al. (2009). Characterization of aroma and agronomic traits in Afghan native rice cultivars. Plant Prod. Sci. 12: 63-69.

von Post R, von Post L, Dayteg C, Nilsson M, et al. (2003). A high-throughput DNA extraction method for barley seed. Euphytica 130: 255-260. 